\title{
Secretion of inhibin A, inhibin B and inhibin pro-aC during the oestrous cycle of the golden hamster (Mesocricetus auratus)
}

\author{
K Ohshima ${ }^{1,4}, \mathrm{H} \mathrm{Kishi}^{2}, \mathrm{M}$ Itoh $^{3}, \mathrm{G}$ Watanabe ${ }^{1}, \mathrm{~K} \mathrm{Arai}^{4}$, \\ K Uehara ${ }^{4}$, N P Groome ${ }^{5}$ and K Taya ${ }^{1}$ \\ ${ }^{1}$ Laboratory of Veterinary Physiology, Tokyo University of Agriculture and Technology, 3-5-8 Saiwai-cho, Fuchu, Tokyo 183-8509, Japan \\ ${ }^{2}$ Department of Animal Reproduction, National Institute of Animal Industry, Ministry of Agriculture, Forestry and Fisheries, Tsukuba Norin-kenkyu-danchi, \\ Ibaraki 305-0991, Japan \\ ${ }^{3}$ Primate Research Institute, Kyoto University, Inuyama, Aichi 484-8506, Japan \\ ${ }^{4}$ Department of Tissue Physiology and Laboratory of Veterinary Physiology, Faculty of Agriculture, Tokyo University of Agriculture and Technology, \\ Tokyo 183-8509, Japan \\ ${ }^{5}$ School of Biological and Molecular Sciences, Oxford Brookes University, Headington, Oxford OX3 OBP, UK \\ (Requests for offprints should be addressed to K Taya)
}

\begin{abstract}
Plasma concentrations of inhibin pro- $\alpha \mathrm{C}$, inhibin $\mathrm{A}$ and inhibin B were determined by enzyme-linked immunosorbent assay at $6 \mathrm{~h}$ intervals throughout the 4-day oestrous cycle of the golden hamster. Plasma concentrations of follicle-stimulating hormone (FSH) and oestradiol-17 $\beta$ were also measured by radioimmunoassay during the oestrous cycle.

Plasma concentrations of inhibin A increased from the early morning of day 1 (day $1=$ day of ovulation) and reached plateau levels at $0500 \mathrm{~h}$ on day 2. An abrupt increase in plasma concentrations of inhibin A was found at $1700 \mathrm{~h}$ on day 4, when the preovulatory FSH surge was observed. An increase in plasma concentrations of inhibin $\mathrm{B}$ occurred on day 1 and reached plateau levels at $1700 \mathrm{~h}$ on day 1. The levels remained elevated until $0500 \mathrm{~h}$ on day 4 and declined gradually by $2300 \mathrm{~h}$ on day 4 . Plasma concentrations of inhibin pro- $\alpha \mathrm{C}$ gradually increased with
\end{abstract}

some fluctuation from day 1 to $1700 \mathrm{~h}$ on day 4 and then declined. Significant negative relationships were noted between plasma FSH and both dimeric forms of inhibin from day 1 to day 3 . Significant positive relationships were found between plasma oestradiol-17 $\beta$ and inhibin A or inhibin pro- $\alpha \mathrm{C}$ throughout the oestrous cycle. In contrast, no significant relationship was found between plasma oestradiol-17 $\beta$ and inhibin B.

These findings suggest that both dimeric forms of inhibin play a role in the regulation of FSH secretion during follicular development. These findings also suggest that inhibin pro- $\alpha \mathrm{C}$ could be secreted primarily by large follicles, and early atretic follicles could also be responsible for inhibin pro- $\alpha \mathrm{C}$ secretion. On the other hand, the secretory pattern of dimeric inhibins might shift from inhibin B to inhibin A with follicular development.

Journal of Endocrinology (1999) 162, 451-456

\section{Introduction}

The reproductive cycle of the golden hamster (Mesocricetus auratus) has some unique characteristics. For example, the corpus luteum in the cyclic ovary always begins to show signs of histological regression by 3 days after ovulation and almost completely vanishes by the next ovulation (Grady \& Greenwald 1968). In addition, the follicle-stimulating hormone (FSH) surge during the periovulatory period is clearly separated into two peaks in the hamster (Bast \& Greenwald 1974), unlike the rat in which the FSH surges almost overlap (Watanabe et al. 1990).

Inhibin is a polypeptide hormone secreted by granulosa cells of the ovary in the female and is thought to be a primary factor in the regulation of $\mathrm{FSH}$ secretion in mammals (De Jong 1988, Ying 1988). Our previous work showed that inhibin is more effective than oestradiol-17 $\beta$ in suppressing FSH secretion and suggested that ovarian inhibin plays a primary role in the regulation of FSH secretion during the oestrous cycle in the hamster (Kishi et al. 1997). Another of our previous studies suggested that inhibin is a key factor for determining the species-specific ovulation rates through the regulation of FSH secretion (Kishi et al. 1996, Taya et al. 1996).

Recently, a new enzyme-linked immunosorbent assay (ELISA) has been developed by Groome and colleagues (Groome \& Lawrence 1991, Groome et al. 1995, 1996) that has been adapted to the specific measurement of different circulating forms of inhibin. Since then, the changing pattern of concentration in the plasma of each form of inhibin has been reported in some species such as the human (Groome et al. 1996) and the rat (Woodruff et al. 1996). 
In this study, we measured the concentrations of inhibin $\mathrm{A}$, inhibin $\mathrm{B}$ and inhibin pro- $\alpha \mathrm{C}$ during the oestrous cycle in the golden hamster using ELISA. Plasma concentrations of FSH and oestradiol-17 $\beta$ were also determined using radioimmunoassay to investigate the relationship between each form of inhibin and follicular development, and the ability of inhibins to regulate FSH secretion in the cyclic golden hamster.

\section{Materials and Methods}

Animals

Adult female golden hamsters (Mesocricetus auratus) were maintained under controlled temperature and lighting (lights on from $0500 \mathrm{~h}$ to $1900 \mathrm{~h}$ ). Food and water were available ad libitum. The 4-day oestrous cycle was determined by the presence of a characteristic vaginal discharge on the morning of the day of ovulation which was designated day 1 of the cycle. Hamsters with at least two consecutive 4-day oestrous cycles were used in this study.

\section{Plasma samples}

Animals were killed by decapitation at $6 \mathrm{~h}$ intervals during the oestrous cycle and trunk blood obtained from each animal was collected into the respective heparinized centrifuge tube. For characterization of inhibin A, inhibin $\mathrm{B}$ and inhibin pro- $\alpha \mathrm{C}$ ELISAs, plasma samples were collected from 5 pregnant hamsters on pregnant day 12 (day 0 of pregnancy $=$ day of positive sperm). Plasma samples were separated by centrifugation at $1700 \boldsymbol{g}$ for $10 \mathrm{~min}$ at $4{ }^{\circ} \mathrm{C}$ and stored at $-20{ }^{\circ} \mathrm{C}$ until assayed.

\section{Ovarian homogenate}

Animals were killed by decapitation and ovaries were collected and stored at $-20{ }^{\circ} \mathrm{C}$ in $1 \mathrm{ml} 0 \cdot 85 \%(\mathrm{w} / \mathrm{v}) \mathrm{NaCl}$ solution. Ovaries were thawed on ice, homogenized using a homogenizer (UR 200P; Tomy, Tokyo, Japan) and centrifuged at $25000 \mathrm{~g}$ for $30 \mathrm{~min}$ at $4{ }^{\circ} \mathrm{C}$. Supernatants were stored at $-20^{\circ} \mathrm{C}$ until assayed for inhibin A, inhibin $\mathrm{B}$ and inhibin pro- $\alpha \mathrm{C}$.

\section{Inhibin $A$, inhibin $B$ and inhibin pro- $\alpha C$ ELISAs}

Inhibin $\mathrm{A}$, inhibin $\mathrm{B}$, and inhibin pro- $\alpha \mathrm{C}$ assays were purchased from Serotec (Oxford, Oxon, UK), and the characteristics of these dimer-specific assays have been described previously. Amounts of inhibin A and inhibin B were expressed in terms of recombinant human inhibin A (Groome \& Lawrence 1991) and recombinant human inhibin B (Groome et al. 1996) respectively. The amount of inhibin pro- $\alpha \mathrm{C}$ was expressed in terms of the purified inhibin pro- $\alpha \mathrm{C}$ from human follicular fluid (Groome et al. 1995).

\section{Radioimmunoassay of FSH and oestradiol-17 $\beta$}

Concentrations of FSH in plasma were measured using NIDDK RIA kits for rat FSH as described previously (Bast \& Greenwald 1974). Iodinated preparations were rat FSH-I-5. The antiserum used was anti-rat FSH-S-11. Results were expressed in terms of NIDDK rat FSH-RP-2.

Concentrations of oestradiol-17 $\beta$ in plasma were measured by double-antibody RIA systems using $\mathrm{I}^{125}$ labelled radioligands as described previously (Taya et al. 1985). Antiserum against oestradiol-17 $\beta$ (GDN 244; Korenman et al. 1974) was kindly provided by Dr G D Niswender (Colorado State University, Fort Collins, CO, USA).

\section{Statistics}

The linear coefficients of correlation $(r)$ were calculated between the following pairs: plasma levels of FSH and three types of inhibin, oestradiol-17 $\beta$ and three types of inhibin, inhibin $\mathrm{A}$ and inhibin $\mathrm{B}$, inhibin $\mathrm{A}$ and inhibin pro- $\alpha \mathrm{C}$, inhibin $\mathrm{B}$ and inhibin pro- $\alpha \mathrm{C}$. A value of $P<0 \cdot 05$ was considered to be statistically significant.

In the inhibin assays, dilutions of plasma and homogenized samples were used to check for parallelism with the human inhibin standards by $2 \times 2$ point analysis.

\section{Results}

Characterization of inhibin $A$, inhibin $B$ and inhibin pro- $\alpha C$ assays

Displacement of each tracer with the ovarian homogenate and peripheral plasma of pregnant hamsters produced excellent dose-response curves in the inhibin A (Fig. 1a), inhibin B (Fig. 1b) and inhibin pro- $\alpha$ C (Fig. 1c) assays. Each replacement curve was parallel with the respective standard curve, indicating that it is possible to measure the concentration of inhibin A, inhibin B and inhibin pro- $\alpha \mathrm{C}$ in peripheral plasma of the female hamster using present ELISA systems.

\section{Changes in plasma concentrations of inhibins}

Plasma concentrations of inhibin A increased from $0500 \mathrm{~h}$ on day 1 , when the concentration was at its lowest, and reached plateau levels at $0500 \mathrm{~h}$ on day 2 (Fig. 2a). An abrupt increase in the plasma concentrations of inhibin A was found at $1700 \mathrm{~h}$ on day 4 and the concentration then declined rapidly until $2300 \mathrm{~h}$ on day 4 .

An increase in plasma concentrations of inhibin B occurred before $0500 \mathrm{~h}$ on day 1 and reached plateau levels at $1700 \mathrm{~h}$ on the same day (Fig. 2b). The levels remained high until $0500 \mathrm{~h}$ on day 4 and declined gradually by $2300 \mathrm{~h}$ on day 4 , when the level was at its lowest. 

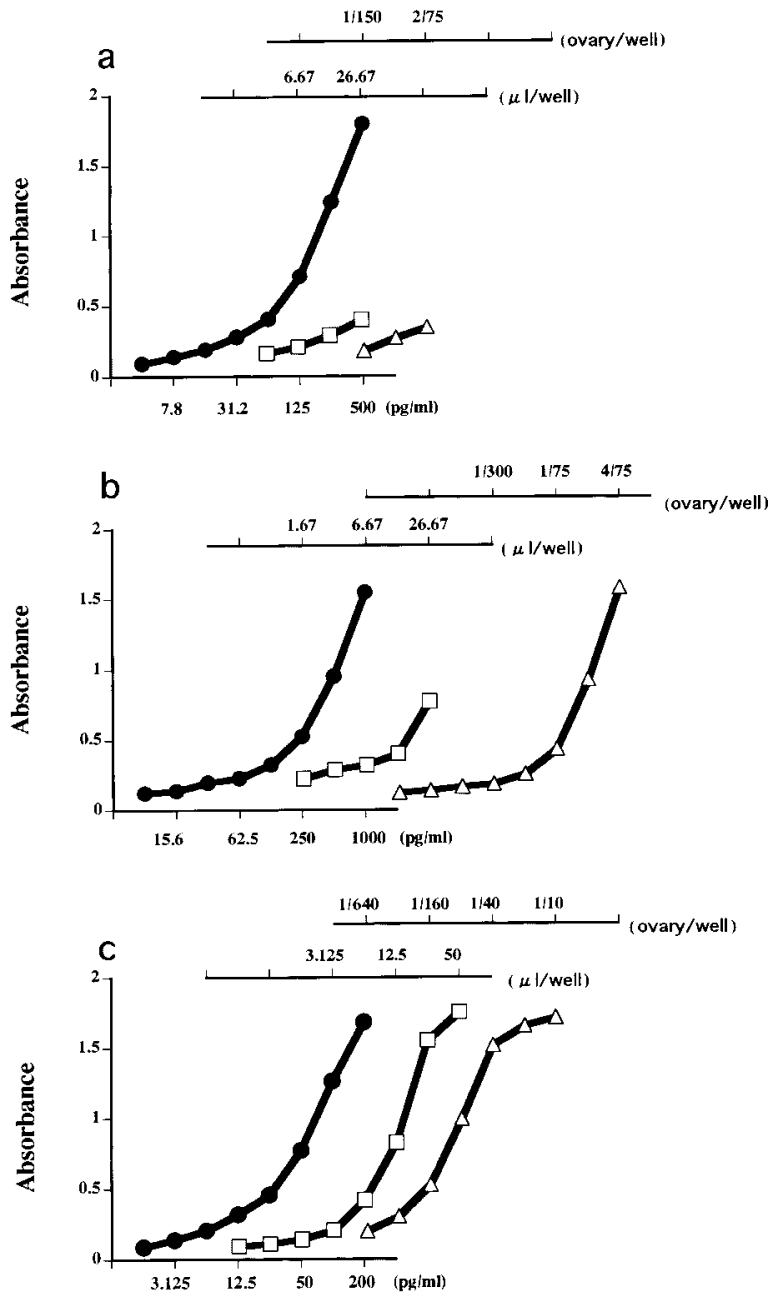

Figure 1 Dose-response curves of standard $(\bullet)$, plasma $(\square)$ and ovarian homogenates $(\triangle)$ of female golden hamsters in ELISAs for (a) inhibin A, (b) inhibin B and (c) inhibin pro- $\alpha \mathrm{C}$.

Plasma concentrations of inhibin pro- $\alpha \mathrm{C}$ gradually increased with some fluctuation from $0500 \mathrm{~h}$ on day 1 , when the level was at its lowest (Fig. 2c). Concentrations of inhibin pro- $\alpha \mathrm{C}$ continued to increase until $1700 \mathrm{~h}$ on day 4 and then the levels declined.

A positive relationship between the changing patterns of inhibin A and inhibin B was found from day 1 to day 3 of the oestrous cycle $(r=0 \cdot 642$; degrees of freedom (d.f.) $=58)$. On day 4, no relationship was found between them. On the other hand, a positive relationship was found between inhibin $\mathrm{A}$ and inhibin pro $\alpha \mathrm{C}(r=0.776$; d.f. $=58)$, and inhibin $\mathrm{B}$ and inhibin pro- $\alpha \mathrm{C}(r=0.575$; d.f. $=58)$ from day 1 to day 3 of the oestrous cycle.

Relationship between changes in plasma concentrations of FSH and three types of inhibin

The second surge of FSH was finished by the afternoon of day 1 and abruptly declining plasma concentrations of FSH

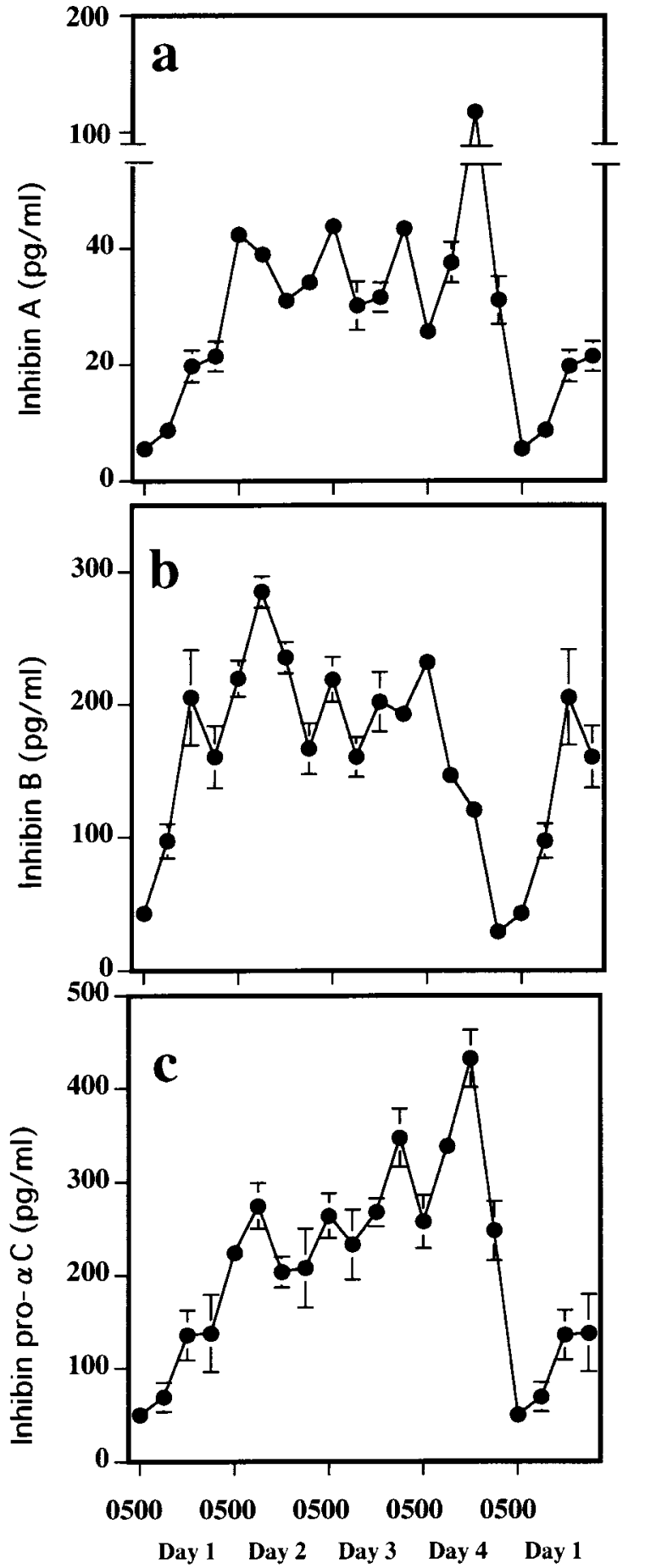

Time and stages of the oestrous cycle

Figure 2 Changes in plasma concentrations of (a) inhibin A, (b) inhibin $\mathrm{B}$ and (c) inhibin pro- $\alpha \mathrm{C}$ during the 4-day oestrous cycle of the golden hamster. Animals were killed at $6 \mathrm{~h}$ intervals throughout the oestrous cycle. The day of ovulation was designated as day 1 of the oestrous cycle. Each value represents the means \pm S.E.M. of five observations. 
were found from $1700 \mathrm{~h}$ to $2300 \mathrm{~h}$ on day 1 . Then plasma concentrations of FSH gradually decreased with some fluctuation up to $2300 \mathrm{~h}$ on day 3. During this period, a strong negative relationship was found between the changing pattern of plasma concentrations of FSH and each type of inhibin, inhibin A $(r=-0 \cdot 716$; d.f. $=58)$ (Fig. 3a), inhibin B $(r=-0 \cdot 456 ;$ d.f. $=58) \quad$ (Fig. $3 b)$ and inhibin pro- $\alpha \mathrm{C}$ $(r=-0.678$; d.f. $=58)$ (Fig. 3c) respectively.

Plasma concentrations of FSH were at low levels in the morning of day 4 and the preovulatory surge occurred at $1700 \mathrm{~h}$ on the same day. At the time of the preovulatory surge of FSH, plasma concentrations of both inhibin A and inhibin pro- $\alpha \mathrm{C}$ increased and reached their highest levels. The changing patterns of both types of plasma inhibin corresponded to that of plasma FSH and a positive relationship was found between the changing pattern of plasma FSH and both types of inhibin, inhibin A $(r=0 \cdot 949$; d.f. $=18)$ and inhibin pro- $\alpha \mathrm{C}(r=0593$; d.f. $=18)$. On the other hand, plasma concentrations of inhibin B were decreasing and no positive relationship was found between changes in plasma FSH and inhibin B $(r=-0 \cdot 155$; d.f. $=18)$.

Relationship between plasma concentrations of oestradiol-17 $\beta$ and each type of inhibin

Plasma concentrations of oestradiol-17 $\beta$ gradually increased from $0500 \mathrm{~h}$ on day 1 to $2300 \mathrm{~h}$ on day 3 and then decreased until the morning of day 4 . Thereafter, plasma concentrations of oestradiol-17 $\beta$ increased up to $1700 \mathrm{~h}$ on day 4 when the preovulatory FSH surge occurred. Throughout the oestrous cycle, positive relationships were found between the changing pattern of plasma oestradiol $-17 \beta$ and inhibin A $(r=0.509$; d.f. $=78)$ (Fig. 4a) and inhibin pro- $\alpha \mathrm{C}(r=0.615$; d.f. $=78)$ (Fig. $4 b)$. On the other hand, no relationship was found between the changing pattern of oestradiol-17 $\beta$ and inhibin $\mathrm{B}$ $(r=0 \cdot 156$; d.f. $=78)($ Fig. 4c).

\section{Discussion}

After ovariectomy, plasma concentrations of all forms of inhibin molecules determined in the present study were reduced to below the limit of detection, indicating that these inhibin forms originated from the ovary in the female golden hamster, as they do in female rats (Groome et al. 1995).

Although a positive relationship was found between the changing pattern of plasma inhibin A and inhibin B from day 1 to day 3 of the cycle, no relationship was found between these two forms on day 4 . This finding suggests that the source of inhibin A may be different from that of inhibin $\mathrm{B}$, or that the secretion pattern of each inhibin form may be dramatically shifted in some follicles, especially on day 4 . On the other hand, the changing pattern of plasma concentrations of oestradiol-17 $\beta$ corre-

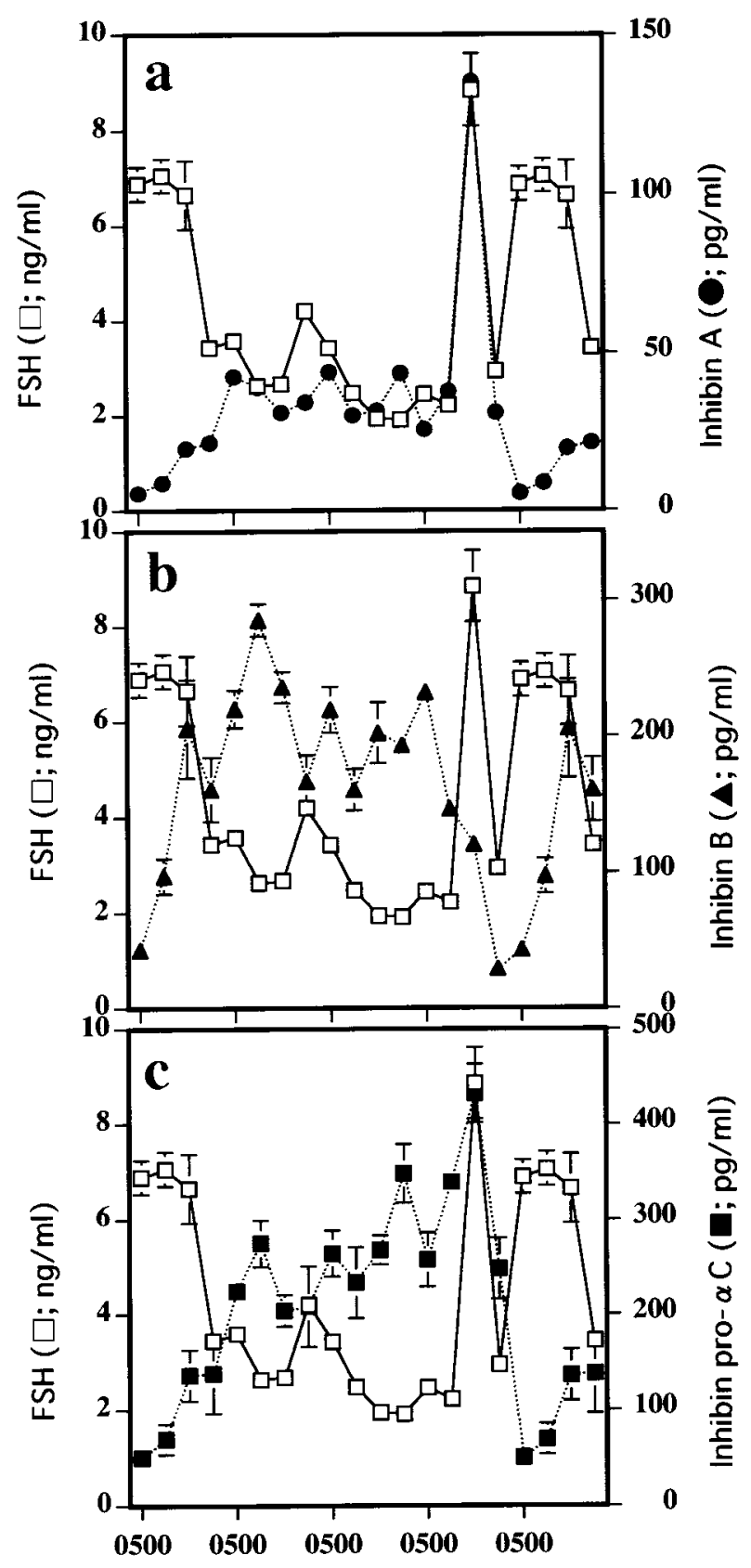

Day 1 Day 2 Day 3 Day 4 Day 1

Time and stages of the oestrous cycle

Figure 3 The correlation between plasma concentrations of FSH and each molecule of inhibin ((a) inhibin A; (b) inhibin B; (c) inhibin pro- $\alpha \mathrm{C}$ ). Changes in plasma concentrations of $\mathrm{FSH}$ during the oestrous cycle are shown in each panel. Each point represents the means \pm S.E.M. of five observations.

sponded better with that of inhibin A than with that of inhibin B during the period. Our previous study (Kishi et al. 1995) demonstrated that the changing pattern of 


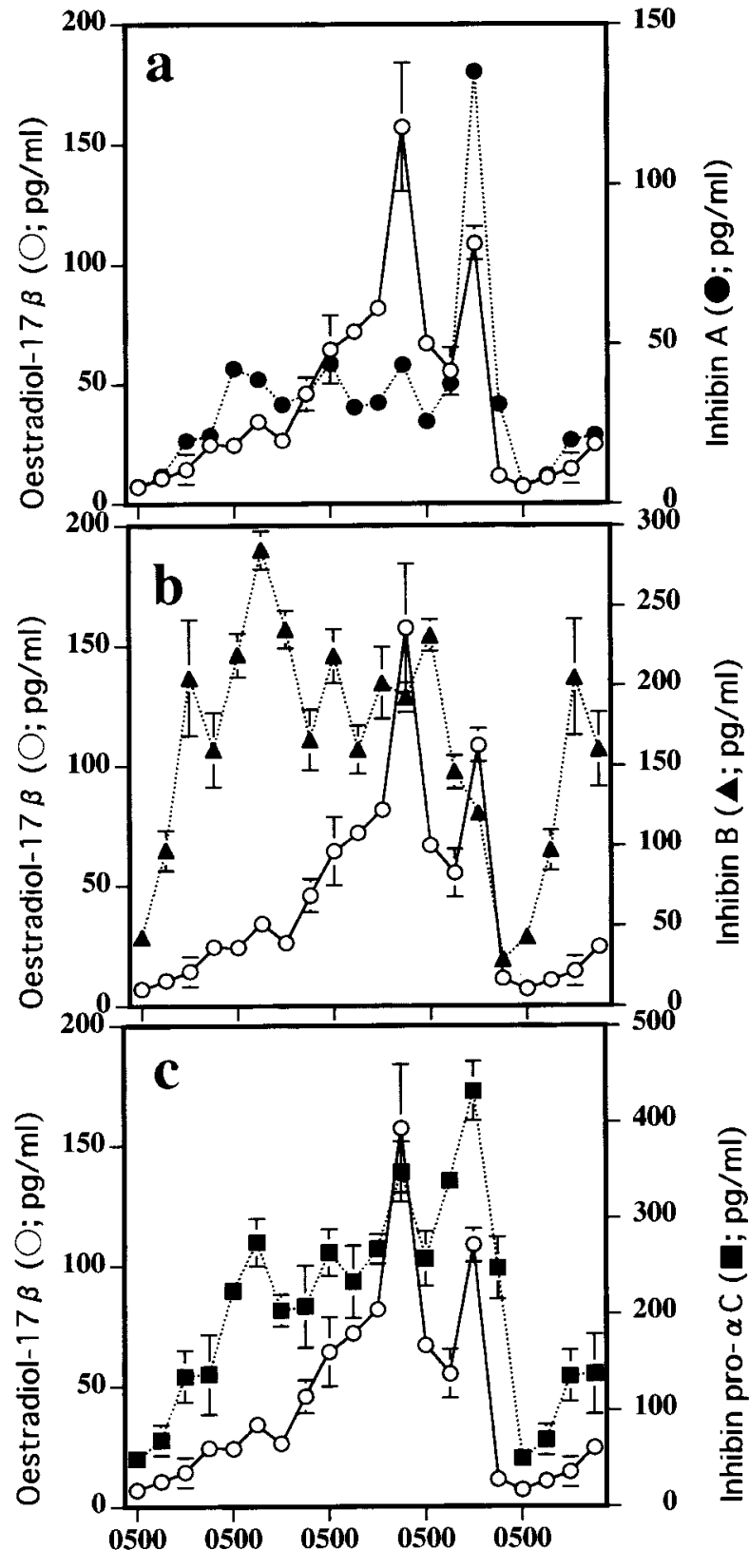

Day 1 Day 2 Day 3 Day 4 Day 1

Time and stages of the oestrous cycle

Figure 4 The correlation between plasma concentrations of oestradiol-17 $\beta$ and each molecule of inhibin ((a) inhibin A; (b) inhibin $B$; (c) inhibin pro- $\alpha C$ ). Changes in plasma concentrations of oestradiol- $17 \beta$ during the oestrous cycle are shown in each panel. Each point represents the means \pm S.E.M. of five observations.

plasma concentrations of oestradiol-17 $\beta$ corresponded well with the number of large antral follicles. From the night of day 3 to the morning of day 4 , the range of follicles shifts to the larger size but the number of large follicles decreases by a half (Greenwald 1961). Smitz \& Cortvrindt (1998) also demonstrated that in mice inhibin $\mathrm{B}$ was the most sensitive marker for proliferation of the early stages of follicles, while inhibin A secretion became predominant at later stages. These findings suggest that the changes in plasma concentration of inhibin A reflect the number of large antral follicles in the ovary. On the other hand, the secretion of inhibin B from developed large antral follicles would be reduced, and the smaller follicles and early atretic follicles might be responsible for the secretion of inhibin B especially in the morning of day 4 . In another report using the rat inhibin $\beta \mathrm{B}$ subunit mRNA expression in tertiary follicles was found to be decreased from the morning of dioestrus to the morning of proestrus while inhibin $\beta$ A did not change (Meunier et al. 1988).

A gradual increase in the concentration of inhibin pro- $\alpha \mathrm{C}$ was found until the time of the preovulatory FSH surge and the changing pattern corresponded to the concentration of inhibin A and oestradiol-17 $\beta$ in the plasma, suggesting that large antral follicles are responsible for the changes in circulating inhibin pro- $\alpha \mathrm{C}$. However, only a small and temporal drop was found in plasma inhibin pro- $\alpha \mathrm{C}$, although a clear decreasing phase was found in plasma oestradiol- $17 \beta$ from the night of day 3 to the morning of day 4 . About a half of large antral follicles enter atresia in the cyclic hamster during this period (Greenwald 1961). Taken together, these results suggest that preantral follicles and early atretic follicles, as well as large follicles, are also responsible for the concentrations of inhibin pro- $\alpha \mathrm{C}$ in the plasma. This is also supported by our previous study of immunostaining of inhibin $\alpha$ subunit in various sized follicles in the golden hamster (Otsuka et al. 1997).

Significant negative relationships were noted between plasma FSH and both dimeric forms of inhibin from day 1 to day 3 , suggesting that both forms of inhibin play a role in the regulation of FSH secretion at least during this period. On the basis of this finding and that described above, it is possible to put forward the following sequence of events: the preovulatory gonadotrophin surges cause ovulation in the early morning of day 1 . They remove the negative regulation of dimeric forms of inhibin on $\mathrm{FSH}$ secretion and cause the second FSH surge on day 1 of the cycle. The recruited follicles stimulated by the high levels of FSH start to secrete all forms of inhibins, especially inhibin B, from early on day 1 . Then large antral follicles appear in the ovary during the night of day 1 and total amounts of inhibins, especially inhibin A, increase from the ovaries. These increasing plasma concentrations of inhibins suppress FSH secretion and terminate the second FSH surge. At the early stage of the oestrous cycle, inhibin $\mathrm{B}$ secreted from developing preantral follicles may be important for suppression of the second FSH surge since this form of inhibin increased quickly in the circulation after ovulation. 
The changing pattern of plasma inhibin pro- $\alpha \mathrm{C}$ concentration has a negative relationship to that of plasma FSH. However, it is thought that free forms of inhibin $\alpha$-subunit, including inhibin pro- $\alpha \mathrm{C}$, and inhibin- $\alpha \mathrm{C}$ may not have a negative function on FSH secretion and may have functions quite distinct from dimeric inhibins (Sugino et al. 1989). Some evidence for this exists, as immunization of inhibin $\alpha$ subunit impairs fertility by unknown mechanisms (Findlay et al. 1994), and inhibin pro- $\alpha \mathrm{C}$ is claimed to modulate the binding of FSH to its receptor (Schneyer et al. 1991).

In conclusion, dimeric forms of inhibins are mainly secreted from the healthy follicles in cyclic golden hamsters. Depending on follicular development, the secretory patterns of the different forms of inhibin might gradually shift from inhibin $\mathrm{B}$ to inhibin $\mathrm{A}$. On the other hand, inhibin pro- $\alpha \mathrm{C}$ may be secreted from healthy developing follicles. In addition early atretic follicles may also be an important source of inhibin pro- $\alpha \mathrm{C}$.

\section{Acknowledgements}

We are grateful to the Rat Pituitary Hormone Distribution Program, NDDK, NIH, USA for RIA materials; Dr G D Niswender, Colorado State Univeristy, Fort Collins, CO, USA for antisera to oestradiol (GDN224); and Teikoku Hormone, MFG Co. Ltd, Tokyo, Japan for oestradiol-17 $\beta$. This work was supported in part by US-Japan cooperative Research Grant from the Japan Society for Promotion of Science.

\section{References}

Bast JD \& Greenwald GS 1974 Serum profiles of follicle-stimulating hormone, luteinizing hormone and prolactin during the estrous cycle of the hamster. Endocrinology 94 1295-1299.

Findlay JK, Russell DL, Doughton B, Tsonic CG, Borchers C \& Forage RG 1994 Effect of activin immunization against the amino terminal peptide (alpha-N) of the alpha-43-KDa subunit of inhibin (alpha-43) on fertility of ewes. Reproduction, Fertility and Development $6265-267$.

Grady KL \& Greenwald GS 1968 Gonadotropic induction of pseudopregnancy in the cyclic hamster. Endocrinology 83 1173-1180.

Greenwald GS 1961 Quantitative study of follicular development in the ovary of the intact or unilaterally ovariectomized hamster. Journal of Reproduction and Fertility 2 351-361.

Groome N \& Lawrence M 1991 Preparation of monoclonal antibodies to the beta A subunit of ovarian inhibin using a synthetic peptide immunogen. Hybridoma 10 309-316.

Groome NP, Illingworth JP, O’Brien M, Priddle J, Weaver K \& McNeilly AS 1995 Quantification of inhibin pro- $\alpha \mathrm{C}$-containing forms in human serum by a new ultrasensitive two-site enzymelinked immunosorbent assay. Journal of Clinical Endocrinology and Metabolism 80 2962-2932.
Groome NP, Illingworth PJ, O’Brien, Pai R, Rodger FE, Mather JP \& McNeilly AS 1996 Measurement of dimeric inhibin B throughout the human menstrual cycle. Journal of Clinical Endocrinology and Metabolism 81 1401-1405.

de Jong FH 1998 Inhibin. Physiological Reviews 68 555-607.

Kishi H, Taya K, Watanabe G \& Sasamoto S 1995 Follicular dynamics and secretion of inhibin and oestradiol- $17 \beta$ during the oestrous cycle of the hamster. Journal of Endocrinology 146 169-176.

Kishi H, Okada T, Otsuka M, Watanabe G, Taya K \& Sasamoto S 1996 Induction of superovulation by immunoneutralization of endogenous inhibin through the increase in the secretion of follicle-stimulating hormone in the cyclic golden hamster. Journal of Endocrinology 151 65-75.

Kishi H, Okada T, Kawazu S, Otsuka M, Taya K, Watanabe G \& Sasamoto S 1997 Effects of passive immunization against oestradiol-17 $\beta$ and inhibin on the secretion of gonadotrophin in the cyclic golden hamster (Mesocricetus auratus). Reproduction, Fertility and Development 9 447-453.

Korenman SG, Stevens RH, Carpenter LA, Robb M, Niswender GD \& Sherman BM 1974 Estradiol radioimmunoassay without chromatography: procedure, validation and normal values. Journal of Clinical Endocrinology and Metabolism 38 718-720.

Meunire H, Cajander SB, Roberts VJ, Rivier C, Sawchenko PE, Hsueh AJW \& Vale W 1988 Rapid changes in the expression of inhibin $\alpha-, \beta \mathrm{A}$, and $\beta \mathrm{B}$ subunits in ovarian cell types during the rat oestrous cycle. Molecular Endocrinology 2 1352-1363.

Otsuka M, Kishi H, Arai K, Watanabe G, Taya K \& Greenwald GS 1997 Temporal changes in inhibin, steroid hormones, and steroidgenic enzymes during induced follicular atresia in the hypophysectomized cyclic hamster. Biology of Reproduction $\mathbf{5 6}$ 423-429.

Schneyer AL, Sluss PM, Whitcomb RW, Martin KA, Sprengel R \& Crowley WF Jr 1991 Precursors of alpha-inhibin modulate follicle-stimulating hormone receptor binding and biological activity. Endocrinology 129 1987-1999.

Smitz J \& Cortvrindt R 1998 Inhibin A and inhibin B secretion in mouse preantral follicle culture. Human Reproduction 13 927-935.

Sugino K, Nakamura T, Takio K, Titani K, Miyamoto K, Hasegawa Y, Igarashi M \& Sugino H 1989 Inhibin alpha-subunit monomer is present in bovine follicular fluid. Biochemical Biophysiology Research Community 31 1323-1329.

Taya K, Watanabe G \& Sasamoto S 1985 Radioimmunoassay for progesterone, testosterone and estradiol- $17 \beta$ using ${ }^{125}$ I-iodohistamine radioligands. Japanese Journal of Animal Reproduction 31 186-197.

Taya K, Kaneko H, Taketomi T, Kishi H \& Watanabe G 1996 Role of inhibin in the regulation of FSH secretion and folliculogenesis in cows. Animal Reproduction Science 42 563-570.

Watanabe G, Taya K \& Sasamoto S 1990 Dynamics of ovarian inhibin secretion during the oestrous cycle of the rat. Journal of Endocrinology 126 151-157.

Woodruff TK, Besecke LM, Groome N, Draper LB, Schwartz NB \& Weiss J 1996 Inhibin A and inhibin B are inversely correlated to follicle-stimulating hormone, yet are discordant during the follicular phase of the rat estrous cycle, and inhibin A is expressed in a sexually dimorphic manner. Endocrinology 137 5463-5467.

Ying S-Y 1988 Inhibins, activins, and follistatins: gonadal proteins modulating the secretion of follicle-stimulating hormone. Endocrine Review 9 267-293.

Received 6 January 1999

Revised manuscript received 25 March 1999

Accepted 20 April 1999 